\title{
Dietary patterns among older Europeans: the EPIC-Elderly study
}

Christina Bamia ${ }^{1}$, Philippos Orfanos ${ }^{1}$, Pietro Ferrari ${ }^{2}$, Kim Overvad ${ }^{3}$, Heidi H. Hundborg ${ }^{4}$, Anne Tjønneland ${ }^{5}$, Anja Olsen ${ }^{5}$, Emmanuelle Kesse ${ }^{6}$, Marie-Christine Boutron-Ruault ${ }^{7}$, Françoise Clavel-Chapelon ${ }^{6}$, Gabriele Nagel $^{8}$, Paolo Boffetta ${ }^{2,8}$, Heiner Boeing 9 , Kurt Hoffmann ${ }^{9}$, Dimitrios Trichopoulos ${ }^{1,10}$, Nikos Baibas ${ }^{1}$, Theodora Psaltopoulou ${ }^{1}$, Teresa Norat ${ }^{2}$, Nadia Slimani ${ }^{2}$, Domenico Palli ${ }^{11}$, Vittorio $\operatorname{Krogh}^{12}$, Salvatore Panico ${ }^{13}$, Rosario Tumino $^{14}$, Carlotta Sacerdote ${ }^{15}$, H. B. Bueno-de-Mesquita ${ }^{16}$, Marga C. Ocké ${ }^{16}$, Petra H. Peeters ${ }^{17}$, Caroline T. van Rossum ${ }^{16}$, José-Ramón Quirós ${ }^{18}$, Maria-José Sánchez ${ }^{19}$, Carmen Navarro ${ }^{20}$, Aurelio Barricarte ${ }^{21}$, Miren Dorronsoro $^{22}$, Göran Berglund ${ }^{23}$, Elisabet Wirfältt ${ }^{23}$, Göran Hallmans ${ }^{24}$, Ingegerd Johansson ${ }^{24}$, Sheila Bingham ${ }^{25}$, Kay-Tee Khaw ${ }^{26}$, Elizabeth A. Spencer ${ }^{27}$, Andrew W. Roddam ${ }^{27}$, Elio Riboli ${ }^{2}$ and Antonia Trichopoulou ${ }^{1 *}$

${ }^{1}$ Department of Hygiene and Epidemiology, University of Athens Medical School, M. Asias 75, Athens 11527, Greece

${ }^{2}$ International Agency for Research on Cancer (IARC-WHO), Lyon Cedex 08, France

${ }^{3}$ Department of Clinical Epidemiology, Aalborg Hospital, Aarhus University Hospital, Denmark

${ }^{4}$ Department of Clinical Epidemiology, Aarhus University Hospital, Denmark

${ }^{5}$ Institute of Cancer Epidemiology, Danish Cancer Society, Copenhagen, Denmark

${ }^{6}$ Equipe E3N-EPIC, INSERM, Institut Gustave Roussy, Villejuif Cedex, Paris, France

${ }^{7}$ Institut Scientifique et Technique de l'Alimentation et de la Nutrition, INSERM U557, CNAM 5, Paris, France

${ }^{8}$ Division of Clinical Epidemiology, German Cancer Research Center, Heidelberg, Germany

${ }^{9}$ Department of Epidemiology, German Institute of Human Nutrition, Potsdam-Rehbrücke, Germany

${ }^{10}$ Department of Epidemiology, Harvard School of Public Health, Boston, MA, USA

${ }^{11}$ Molecular and Nutritional Epidemiology Unit CSPO-Scientific Institute of Tuscany, Florence, Italy

${ }^{12}$ Epidemiology Unit, National Cancer Institute, Milan, Italy

${ }^{13}$ Dipartimento di Medicina Clinica e Sperimentale Federico II University Naples, Italy

${ }^{14}$ Cancer Registry, Azienda Ospedaliera "Civile M.P. Arezzo" Ragusa, Italy

${ }^{15}$ Unit of Cancer Epidemiology, Department of Biomedical Sciences and Human Oncology, University of Turin, Turin, Italy

${ }^{16}$ Centre for Nutrition and Health, National Institute for Public Health and the Environment, Bilthoven, The Netherlands

${ }^{17}$ Julius Center for Health Sciences and Primary Care, University Medical Center, Utrecht, The Netherlands

${ }^{18}$ Dirección General de Salud Pública, Consejería de Salud y Servicios Sanitarios de Asturias, Oviedo, Spain

${ }^{19}$ Andalusian School of Public Health, Granada Cancer Registry, Granada, Spain

${ }^{20}$ Epidemiology Department, Murcia Health Council, Murcia, Spain

${ }^{21}$ Public Health Institute, Navarra, Spain

${ }^{22}$ Public Health Division of Gipuzkoa, Health Department of Basque Country, San Sebastian, Spain

${ }^{23}$ Department of Medicine, Surgery and Orthopaedics, Lund University, Malmö, Sweden

${ }^{24}$ Public Health and Clinical Medicine, Nutritional Research, Umeå University, Umeå, Sweden

${ }^{25}$ MRC Dunn Human Nutrition Unit, Cambridge, UK

${ }^{26}$ Institute of Public Health, University of Cambridge, Cambridge, UK

${ }^{27}$ Cancer Research UK Epidemiology Unit, University of Oxford, Oxford, UK

(Received 31 August 2004 - Revised 8 December 2004 - Accepted 31 January 2005)

Overall dietary patterns have been associated with health and longevity. We used principal component (PC) and cluster analyses to identify the prevailing dietary patterns of 99744 participants, aged 60 years or older, living in nine European countries and participating in the European Prospective Investigation into Cancer and Nutrition (EPIC-Elderly cohort) and to examine their socio-demographic and lifestyle correlates. Two PC were identified: PC1 reflects a 'vegetable-based' diet with an emphasis on foods of plant origin, rice, pasta and other grain rather than on margarine, potatoes and non-alcoholic beverages. PC2 indicates a 'sweet- and fat-dominated' diet with a preference for sweets, added fat and dairy products but not meat, alcohol, bread and eggs. PC1 was 
associated with a younger age, a higher level of education, physical activity, a higher BMI, a lower waist:hip ratio and never and past smoking. PC2 was associated with older age, less education, never having smoked, a lower BMI and waist:hip ratio and lower levels of physical activity. Elderly individuals in southern Europe scored positively on PC1 and about zero on PC2, whereas the elderly in northern Europe scored negatively on PC1 and variably on PC2. The results of cluster analysis were compatible with the indicated dietary patterns. 'Vegetable-based' and a 'sweet- and fat-dominated' diets are prevalent among the elderly across Europe, and there is a north-south gradient regarding their dietary choices. Our study contributes to the identification of groups of elderly who are likely to have different prospects for long-term disease occurrence and survival.

Dietary patterns: Elderly: Cohort study

There is extensive scientific literature on the relation between specific foods, food groups, nutrients and other food components on the one hand, and the incidence of or mortality from several chronic diseases on the other (Hu \& Willett, 2002; Mann, 2002; Key et al. 2004; Srinath Reddy \& Katan, 2004). In addition to single dietary components or nutrients, several studies have focused on the role of the effects of overall dietary patterns on health status and longevity (Trichopoulou et al. 1995, 2003; Slattery et al. 1998; Kumagai et al. 1999; Hu et al. 2000; Kant et al. 2000; Fung et al. 2001a,b; Osler et al. 2001; Terry et al. 2001; Martinez-Gonzalez et al. 2002; Sieri et al. 2004). Interest in dietary patterns has been dictated by the ability of the latter to integrate the complex or subtle interactive effects of many dietary exposures, to accommodate the intercorrelation of nutrients within a diet and to bypass problems created by multiple testing.

Two general approaches have been used for the development of an overall descriptor of a dietary pattern (Trichopoulos \& Lagiou, 2001): The a priori approach builds on previous knowledge concerning the favourable or adverse health effects of various dietary constituents and operates through the calculation of a graded score that identifies groups with 'better' or 'worse' nutritional intakes (Patterson et al. 1994; Kennedy et al. 1995; Trichopoulou et al. 1995, 2003; Huijbregts et al. 1997; Haines et al. 1999; McCullough et al. 2002). The second approach uses the observed dietary data in order to extract, by means of appropriate exploratory statistical methodology, a posteriori dietary patterns.

The a posteriori approach has been used in nutritional studies and has been shown to be a useful tool for identifying groups with different dietary habits (Prevost et al. 1997; McCann et al. 2001; Schulze et al. 2001; Balder et al. 2003; Costacou et al. 2003). The main techniques used for the a posteriori approach are principal component (PC) analysis, related factor analysis and cluster analysis. The common objective of the first two techniques is to reduce the dimensionality of the data, by transforming the original large set of correlated dietary variables into a new, smaller set of uncorrelated variables, which are called principal components or factors. In contrast, the aim of cluster analysis is to classify persons into naturally existing, mutually exclusive groups on the basis of a similarity in food intake.

Concerning the elderly, studies assessing past and current overall dietary patterns are limited, although this group of people has attracted special attention over the past decade. Focusing on the elderly has been motivated by both a genuine interest in this important age group, which is increasing in most countries, and by methodological considerations (the cumulative effects of diet over an extended period and an inherently high frequency of undesirable outcomes). In Europe, studies that have aimed to describe the diet of the elderly by means of overall dietary patterns are either based on the Survey in Europe on Nutrition and the Elderly: a Concerted Action (SENECA) investigation
(Euronut-SENECA, 1991; Schroll et al. 1996; Haveman-Nies et al. 1998, 2001), a multicentre survey of modest sample size (1282 individuals), or have relied on smaller sample sizes of particular elderly populations (Huijbregts et al. 1995). In the USA, studies on the diet of the elderly have focused on small samples of either residents of Boston (Tucker et al. 1992) or Hispanic elders (Lin et al. 2003). In these studies, cluster analysis was the statistical tool used for the a posteriori identification of dietary patterns.

We have used the a posteriori approach by means of PC and cluster analyses to assess the dietary patterns in a large sample of older Europeans, living in nine different European countries and participating in the prospective, multicentre study European Prospective Investigation into Cancer and Nutrition (EPIC) (Riboli et al. 2002; Slimani et al. 2002a). Moreover, we have evaluated, through multiple regression techniques, the dependence of these dietary patterns on socio-demographic and lifestyle variables. Participants were aged 60 years or older at enrolment (EPIC-Elderly project).

\section{Materials and methods}

\section{Recruitment}

A total of 100059 individuals from nine European countries who were aged 60 years or older at recruitment, and who participated in the EPIC study, were included in the EPIC-Elderly project. EPIC is a multicentre cohort study examining the role of diet on the aetiology of cancer and other chronic diseases, under the coordination of the International Agency for Research on Cancer. Details of the design and methods of the EPIC study have been described in detail elsewhere (Riboli et al. 2002; Slimani et al. 2002a).

In brief, 519978 apparently healthy volunteers were recruited into EPIC from ten European countries (Denmark, France, Germany, Greece, Italy, The Netherlands, Norway, Spain, Sweden and the UK), in twenty-two centres, between 1992 and 2000. Study subjects were either recruited from the general population (Greece, Florence, Varese and Naples in Italy, Germany, Bilthoven in The Netherlands, Denmark, Sweden and Norway), or were teachers and school workers (France), patients of general practitioners (Cambridge in the UK), participants in breast cancer screening (Utrecht in The Netherlands), blood donors (included in the cohorts of Granada, Murcia, Navarra, San Sebastian and Asturius in Spain) and their partners (included in the cohorts of Ragusa and Turin in Italy), or health-conscious subjects, many of them with vegetarian eating habits (the majority of individuals in the Oxford cohort). In France, Norway, Utrecht (The Netherlands) and Naples (Italy), only women were enrolled. The study protocol was approved by ethical committees at both the International Agency for Research on Cancer and the participating 
centres. All participants signed an informed consent form before enrolment. All procedures were in line with the Helsinki declaration for human rights.

The objectives of the EPIC-Elderly project were to investigate the prevailing dietary patterns among the European elders (aged 60 years or older at enrolment) and to study the role of these patterns on their health and longevity. Participants from all countries are included in the EPIC-Elderly database, with the exception of Norway, whose cohort is relatively young (all of the Norwegians in the EPIC cohort still being younger than 60 years).

\section{Dietary intakes}

Information on foods and beverages consumed during the year preceding enrolment was collected with the use of instruments that had been developed and validated within each centre. The assessment tools consisted of self- or interviewer-administered quantitative or food-frequency questionnaires.

The results presented in this paper are based on dietary intakes obtained from these food-frequency questionnaires. Standard portion sizes in each country were used for the estimation of consumed quantities, and methods of quantification were standardised between countries by using photographs, household measures depicted in pictures and standardised units. The intake of each food in $\mathrm{g} / \mathrm{d}$ was calculated taking into account standard recipes and edible fractions. Alcohol consumption was expressed in grams of ethanol per day. Total energy intake (in $\mathrm{kJ} / \mathrm{d}$ ) for each participant was also estimated.

Foods were classified according to a common classification into seventeen main groups and 124 subgroups (Slimani et al. 2002b). This classification groups foods that could be described and quantified according to common rules across countries. All the main groups of this classification were considered in the present analysis except 'miscellaneous' (Table 1). In addition, 'soya' ('soya' and 'soya products') was considered. Some food groups were, however, broken down: 'cereals and cereal products' into 'pasta, rice and other grain', 'bread' and 'other cereals'; 'added fats' into 'vegetable oils', 'margarine' and 'butter'; and 'alcoholic beverages' into 'wine' and 'other alcoholic beverages'. The classification processes relied on suggestions from the participating centres, submitted before the collaborative analysis was undertaken.

\section{Lifestyle, anthropometric and medical variables}

Data on a number of lifestyle and health variables were also recorded with the use of a core lifestyle questionnaire, which contained a common set of questions and possible answers for all participating centres. For centres in which lifestyle and health variables had been collected prior to EPIC initiation, standardisation procedures were developed to ensure the comparability of these variables with those derived from the core EPIC lifestyle questionnaire (Riboli et al. 2002).

Table 1. Food groups and food items included in the analysis of the EPIC-Elderly cohort (From The EPIC-Elderly study)

\begin{tabular}{|c|c|}
\hline Food group & Definition and content \\
\hline Vegetables & $\begin{array}{l}\text { Leafy, fruiting, root, grain, pod and stalk vegetables, mushrooms, alliums, cruciferous, sprouts and } \\
\text { mixed salad/vegetables }\end{array}$ \\
\hline Fruits & Fresh fruits, nuts, seeds, stewed fruit, mixed fruits and olives \\
\hline Potatoes & Potatoes and potato products, except potato crisps \\
\hline Legumes & Dried peas, lentils and beans, except soya \\
\hline \multicolumn{2}{|l|}{ Cereals and cereal products } \\
\hline Pasta, rice and other grain & Pasta, rice, other grain \\
\hline Bread & Bread, crisp bread, rusks \\
\hline Other cereals & $\begin{array}{l}\text { Flour, flakes, starches, breakfast cereals, salty and aperitif biscuits, dough and pastry (puff, } \\
\text { short-crust, pizza) }\end{array}$ \\
\hline Cakes & Cakes, pies, pastries puddings (non-milk-based), dry cakes, biscuits \\
\hline Sugar and confectionery & $\begin{array}{l}\text { Sugar, jam, marmalade, honey, chocolate and products, candy bars, confetti/flakes, drops, boiled } \\
\text { sweets, chewing gum, nougat, cereal bars, marzipan, syrup, water ice }\end{array}$ \\
\hline \multicolumn{2}{|r|}{ 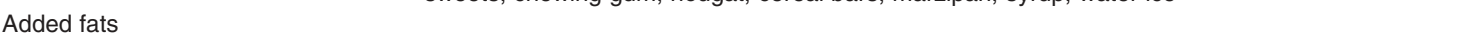 } \\
\hline Vegetable oils & Vegetable oils \\
\hline Margarine & Margarines, mixed dairy margarines, baking fat \\
\hline Butter & Butter, herbal butter, butter concentrate \\
\hline Dairy products & $\begin{array}{l}\text { Liquid milk (e.g. cow's, goat's), processed milk (condensed, dried), whey, milk beverages, yoghurt, } \\
\text { cheeses, cream desserts, puddings (milk-based), dairy creams, ice cream }\end{array}$ \\
\hline Meat and products & $\begin{array}{l}\text { Beef, veal, pork, lamb/mutton, horse, goat, poultry, game and offal, processed meat from red meat or } \\
\text { poultry (e.g. ham, bacon, sausages, pâtés, etc.) }\end{array}$ \\
\hline Eggs & $\begin{array}{l}\text { Eggs (e.g. chicken, turkey, duck, goose, quail) and egg products, except if used for bread and bakery } \\
\text { products }\end{array}$ \\
\hline Fish and shellfish & Fish and fish products, crustaceans and molluscs \\
\hline Non-alcoholic beverages & $\begin{array}{l}\text { Tea (with and without caffeine); iced tea: infusion, powder, instant beverage; coffee (with and without } \\
\text { caffeine): infusion, powder, instant beverage. Carbonated/soft/isotonic drinks, diluted syrups. } \\
\text { Fruit and/or vegetable juices and nectars, freshly squeezed juices: pure or diluted with water }\end{array}$ \\
\hline $\begin{array}{l}\text { Alcoholic beverages } \\
\text { Wine }\end{array}$ & Expressed as ethanol \\
\hline Other alcoholic beverages & Fortified wine, beer, cider, spirits, brandy, aniseed drinks, liqueurs, cocktails \\
\hline Condiments and sauces & $\begin{array}{l}\text { Sauces (tomato sauces, dressing sauces, mayonnaises and similar), yeast, spices, herbs, } \\
\text { flavourings, condiments }\end{array}$ \\
\hline Soups & Soups, bouillon \\
\hline Soya & Soya and products \\
\hline
\end{tabular}


The lifestyle questionnaire included questions on educational achievement, history of previous illnesses, history of smoking and physical activity (occupational and during leisure). For leisure, the time spent on each of a number of activities (in hours per week) was multiplied by an energy cost coefficient to convert hours per week to $\mathrm{kJ}$; all the products were then summed to produce a score of daily physical activity at leisure. To account for possible effects of gender and for the different assessment tools used within centres, gender- and centre-specific tertiles of the estimated physical activity level at leisure were used.

Anthropometric measurements (height, weight, waist and hip circumference) were taken in all EPIC centres using similar, standardised procedures, except for France, Oxford and Norway. In the latter centres, self-reported values for height and weight were recorded instead, with actual measurements being obtained for a fraction of the participants. BMI was calculated as the ratio of weight in kilograms divided by the square of the height in metres. For participants with self-reported weight and height, these values were used in the respective calculations.

\section{Statistical analysis}

PC analysis and cluster analyses were applied to the total EPICElderly cohort as well as separately to males and females. From the initial 100059 Europeans of 60 years or older at recruitment, males from Bilthoven (315) were administratively excluded. The original twenty-two dietary variables (indicated in Table 1) were considered as residuals from linear regressions of each of these on total energy intake over all the centres to control for the role of energy intake on the reported individual food intake (Willett, 1998). In this way, the correlations between foods would be based on dietary choices rather than reflecting between-person variation in overall quantities of intake. We did not include 'centre' in the respective regressions because our objective was to ascertain patterns across Europe rather than within study centres.

$P C$ analysis. Dietary patterns were identified by means of PC extracted from PC analysis (Chatfield \& Collins, 1995). PC were extracted using the correlation matrix in order to adjust for unequal variances of the original variables. To identify the number of PC to be retained, we used the following three commonly used criteria: the criterion of eigenvalues exceeding 1 (the interpretation of this criterion being that each component should explain a larger amount of variance than a single standardised variable in order to be retained), the scree plot (which is a plot of the total variance associated with each component) and the interpretability of each component. Food groups (residuals) with absolute scoring coefficients $>0.2$ were considered to be important contributors to a component (pattern); scoring coefficients indicate the degree of correlation between the original variables (residuals of food group intakes) and the PC extracted. A positive scoring coefficient indicates that the original dietary variable is positively associated with the respective PC, whereas a negative scoring coefficient implies an inverse association. Dietary patterns were expressed as the scores of each PC retained; these were calculated by summing the standardised values of the food groups (residuals) weighted by their scoring coefficients. Thus, each individual received a score for each identified pattern. We labelled patterns on the basis of those food groups, the consumption of which is reflected by high, positive scores in the respective component.
Multiple regression models were fitted for each of the dietary pattern scores on socio-demographic and lifestyle characteristics: gender ('males', 'females'; by category), age ('60-64 years', ' $65-69$ years' and ' $\geq 70$ years'; by category), BMI (in $3 \mathrm{~kg} / \mathrm{m}^{2}$ increments; continuous), waist:hip ratio (in 0.5 unit increments; continuous), total energy intake (in $1257 \mathrm{~kJ}$ (300 kcal) increments; continuous), physical activity at work ('unemployed', 'sedentary occupation', 'standing occupation', 'manual work', 'heavy manual work'; by category), physical activity at leisure time, in centre- and sex-specific tertiles (ordered; continuous), smoking status ('never', 'past', 'current smoker'; by category), educational achievement ('none/primary school completed', 'technical/vocational school completed', 'secondary school completed', 'higher degree'; by category) and centre (by category).

For the purpose of this analysis, the EPIC centres within a country were further aggregated in order to reflect geographical regions that are presumed to share common diets. The five Spanish centres were aggregated into two geographical regions: Northern Spain (San Sebastian, Pamplona, Oviedo) and Southern Spain (Granada, Murcia). The two Danish centres were combined into one, as were the two centres in The Netherlands. In contrast, the UK Oxford centre participants were divided into two, for general population and health-conscious participants (Slimani et al. $2002 b$ ). In all models, France was chosen as the reference category as the dietary habits of French are considered to be somewhere between the diets evident in northern Europe and diets that are typical of people living in southern Europe.

Cluster analysis. Ward's agglomerative method of the minimum variance (Chatfield \& Collins, 1995) was used to cluster individuals into a smaller number of mutually exclusive groups according to their reported daily dietary intake $(\mathrm{g} / \mathrm{d})$ of the same list of twenty-two food groups (as residuals). Cluster analysis is sensitive to outliers so clusters with fewer than ten observations were excluded. The sufficient number of clusters to be retained was assessed by pseudo $\mathrm{F}$, pseudo $\mathrm{t}^{2}$ and cubic clustering criterion, as well as by tree diagrams.

The SAS (SAS Institute Inc., 1999) and STATA (Stata Corporation, 1999) statistical software packages were used.

\section{Results}

Among Europeans aged 60 years or older, the mean energy intake ranged from $8134.6 \mathrm{~kJ} / \mathrm{d}$ in Umeå to $10820 \mathrm{~kJ} / \mathrm{d}$ in Denmark for males, and from $5945.5 \mathrm{~kJ} / \mathrm{d}$ to $9439 \mathrm{~kJ} / \mathrm{d}$ for females at Umiå and Naples respectively. Among men, overall, energy intake was derived as $45 \%$ from carbohydrates, $15 \%$ from protein, $13 \%$ from saturated lipids, $13 \%$ from monounsaturated lipids, $6 \%$ from polyunsaturated lipids and $5 \%$ from ethanol. The contributions of the same macronutrients to total energy intake among women were 46,16,13,13, 6 and $3 \%$, respectively.

Table 2 shows the within-centre average daily intake of each of the twenty-two food groups (original values), as a percentage of the corresponding EPIC-Elderly overall mean for the 99744 elders (34086 men and 65658 women), by gender. There was a high variation between centres in the daily consumption of the indicated food groups, whereas the within-centre respective differences between genders was relatively small.

This table suggests two major dietary profiles among European elders. The first is a northern profile characterised by low consumptions of fruit and pasta/rice/other grain (very low in Germany), vegetables, bread and wine (very low in Sweden), fish (very low 


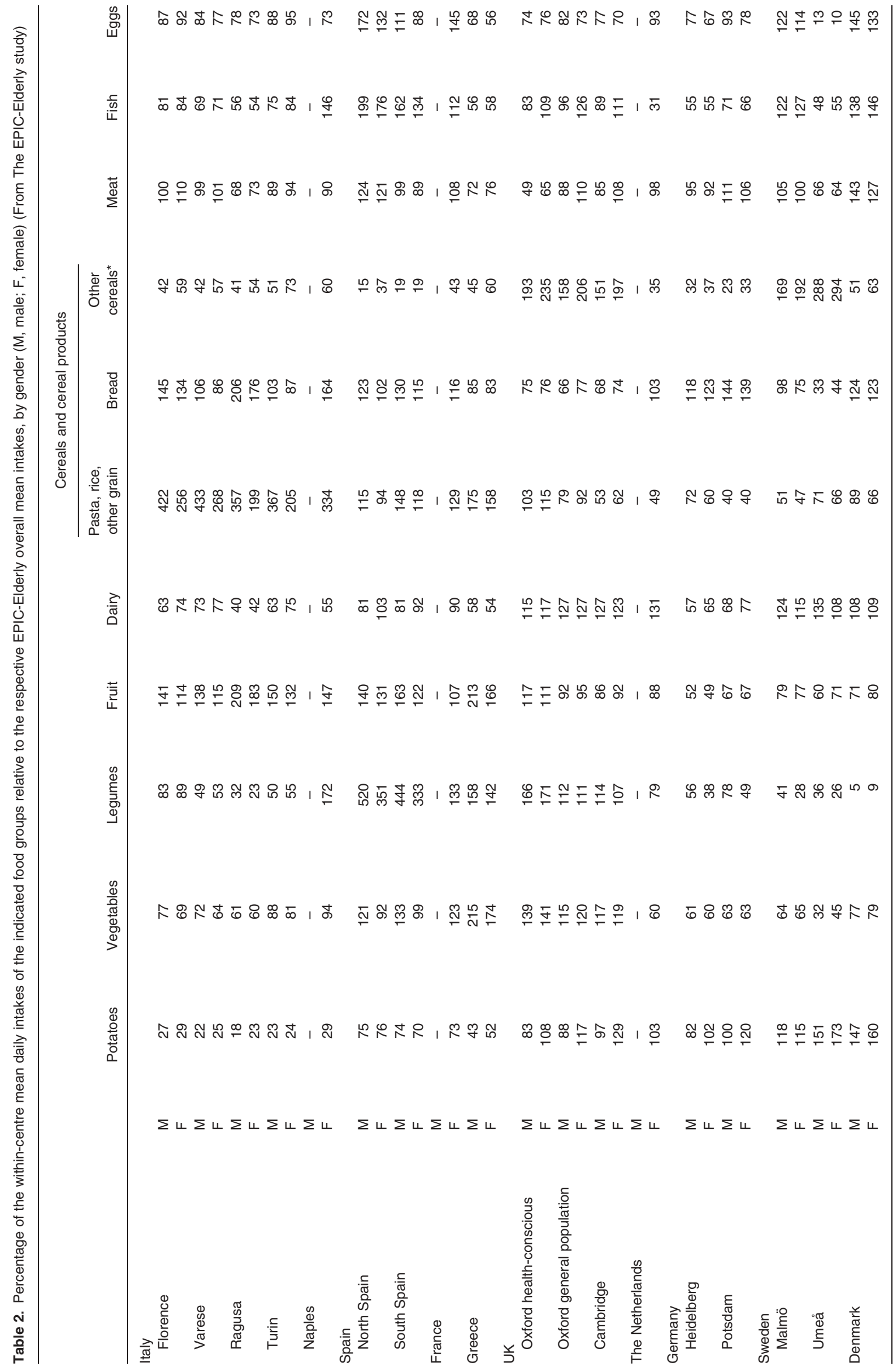




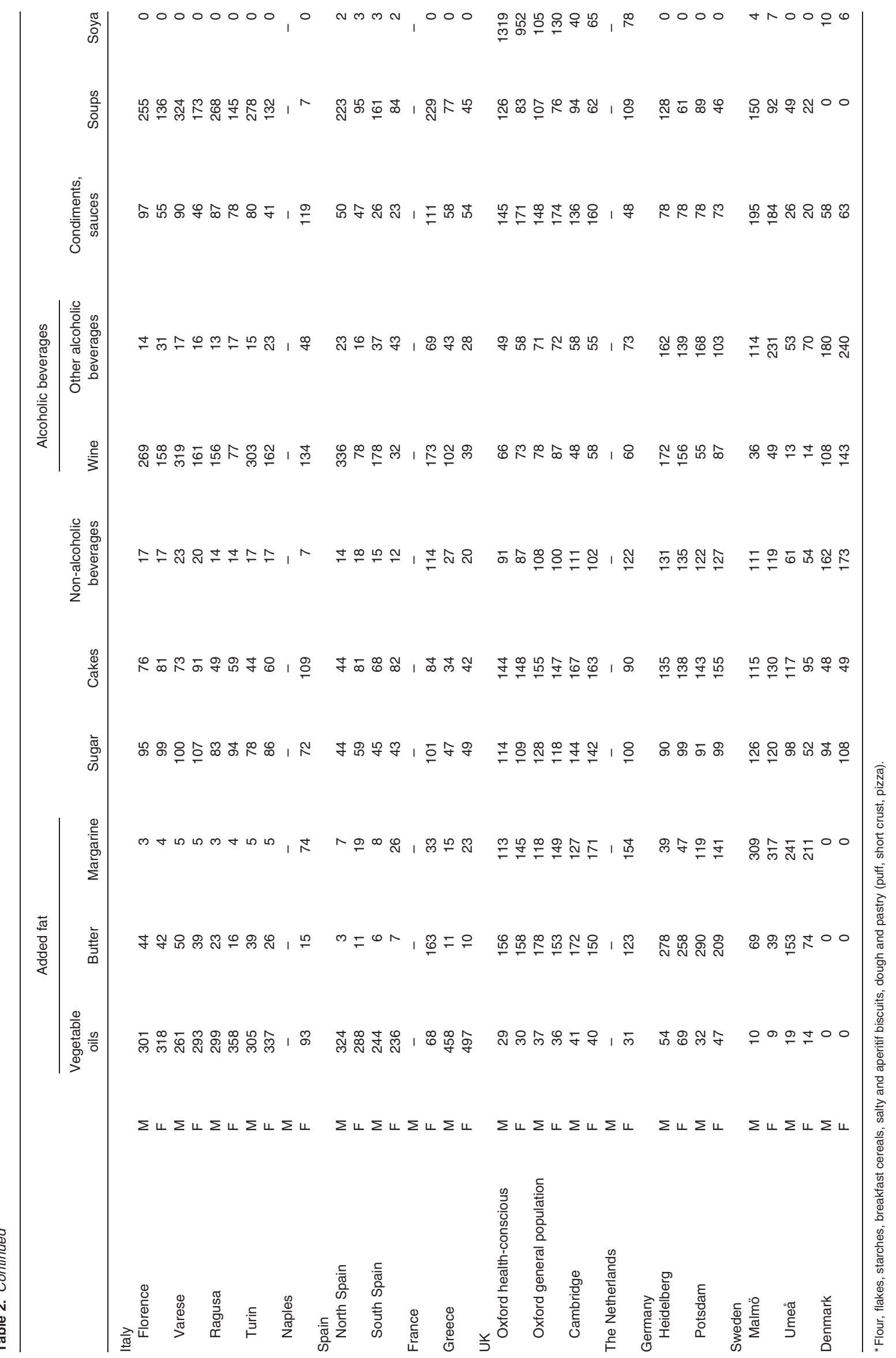


in the Netherlands), legumes and vegetable oils (very low in Denmark), and high consumptions of butter (very high in Germany), potatoes, dairy products and other cereals, such as flour, pastry and breakfast cereals (very high in Sweden), meat, non-alcoholic and alcoholic beverages except for wine (very high in Denmark), and sugar and cakes (very high in Cambridge). The second is a southern profile characterised by a high consumption of vegetables, fruits and vegetable oils (very high in Greece), bread, pasta/rice/other grain and soups (very high in Italy), legumes, fish and wine (very high in Spain), and low consumption of dairy products, non- and other alcoholic beverages (very low in Italy), sugar (very low in Spain) and cakes (very low in Greece).

Table 2 also shows the unique characteristics of diets followed in particular countries that may belong to the same general group. For example, the Italian diet is dominated by pasta, cereals and cereal products, and the Greek diet is characterised by vegetable oils (essentially olive oil), fruit and vegetables, whereas the Spanish diet is characterised by both plant foods and animal food groups (particularly fish and eggs). The mean consumption of soya reaches its highest value in the Oxford health-conscious subjects.

PC and cluster analyses revealed almost identical results for male and female participants of the EPIC-Elderly cohort, hence only findings referring to the total sample are reported. PC analysis identified seven dietary patterns on the basis of the eigenvalue $>1$ criterion. These PC explained approximately $52 \%$ of the total variation in daily food intake. However, the plot of the total variance associated with each PC (scree test), as well as the lack of any meaningful interpretability of some of these components, indicated that the first two PC, explaining approximately $25 \%$ of the total variation, could be used to adequately describe the prevailing dietary patterns among the EPIC-Elderly participants.

Table 3 shows the main constituents of each of the two dominant dietary components, adjusted for total energy intake, in rank order of the absolute value of the positive and negative scoring coefficients. Large coefficients indicate strong associations between the food groups and the corresponding pattern. The food groups contributed to only one specific pattern, with the exception of margarine, which loaded on both of the emerging patterns but with opposite signs. PC1 reflects a 'vegetable-based' diet characterised by a contrast between plant food groups (positive scoring coefficients) and potatoes, margarine and nonalcoholic beverages (negative scoring coefficients). Thus, high positive scores of this component indicate a high consumption of vegetable oils, fruit, pasta, rice and other grain, vegetables and legumes, and a low consumption of non-alcoholic beverages, potatoes and margarine. Evidently, negative scores on PC1 imply the opposite pattern of consumption.

The second PC (PC2) reflects a 'sweet- and fat-dominated' diet with the consumption of sweets and cereals such as flour and savoury snacks, added fat and dairy products (positive values) contrasting with the consumption of bread, meat and eggs, and alcoholic beverages (negative values). Therefore, individuals with high scores on PC2 follow diets with an emphasis on dairy products, cakes, sugar and confectionery, other cereals (flour, pastry, breakfast cereals and similar), margarine, condiments and sauces, whereas they consume small quantities of bread, meat, eggs and alcoholic beverages.

Table 4 shows multiple regression-derived, mutually adjusted partial regression coefficients and their corresponding standard errors, and two-tailed $P$ values of PC1 and PC2 regressed on lifestyle, demographic and anthropometric variables. Partial regression coefficients can be interpreted better than partial correlation coefficients because they have natural dimensions and units, in addition to pointing to the direction of the associations. Only 89560 subjects with complete information on all predictor variables were included in this analysis. The 'vegetable-based' PC1 was positively associated with female gender, higher educational level, total energy intake, physical activity, higher BMI and never and past smoking (as opposed to current smoking). PC1 was inversely associated with age (within the elderly group) and waist:hip ratio. Regarding place of residence, EPIC-Elderly participants living in south Europe had the highest overall scores for PC1, whereas values for this score decrease as we move to countries in the north. An exception to this is the Oxford health-conscious cohort, whose score was slightly lower than the score of France for PC1.

Individuals scoring high on PC2 were more likely to be female, older, less well educated and never smokers, with a lower BMI and waist:hip ratio. Similarly to PC1, PC2 was also positively associated with energy intake but, contrary to the "vegetablebased diet', PC2 was inversely associated with physical activity level at work. Elders living in south Europe had coefficients for PC2 around zero, i.e. noticeably smaller in absolute value than those corresponding to PC1 for the same centres. Northern European centres differed with respect to scores on PC2: whereas UK and Sweden had the highest scores on PC2, Germany

Table 3. Principal components and corresponding scoring coefficients for dietary variables in the EPIC-Elderly population (From The EPIC-Elderly study)

\begin{tabular}{|c|c|c|c|}
\hline Principal components & Positive scoring coefficients & Negative scoring coefficients & Variance explained (\%) \\
\hline $\begin{array}{l}\text { Principal component } 1 \text { (PC1) } \\
\text { 'Vegetable-based' diet }\end{array}$ & $\begin{array}{l}\text { Vegetable oils }(0.46) \\
\text { Fruits }(0.34) \\
\text { Pasta, rice and other grain }(0.34) \\
\text { Vegetables }(0.33) \\
\text { Legumes }(0.25)\end{array}$ & $\begin{array}{l}\text { Non alcoholic beverages }(-0.31) \\
\text { Potatoes }(-0.27) \\
\text { Margarine }(-0.24)\end{array}$ & $14 \cdot 6$ \\
\hline $\begin{array}{l}\text { Principal component } 2 \text { (PC2) } \\
\text { 'Sweet- and fat-dominated' diet }\end{array}$ & $\begin{array}{l}\text { Other cereals }(0.33) \\
\text { Cakes }(0.32) \\
\text { Condiments \& sauces }(0.29) \\
\text { Margarine }(0.28) \\
\text { Sugar and confectionery }(0.22) \\
\text { Dairy products }(0.20)\end{array}$ & $\begin{array}{l}\text { Meat }(-0.36) \\
\text { Bread }(-0.28) \\
\text { Other alcoholic beverages }(-0.26) \\
\text { Wine }(-0.25) \\
\text { Eggs }(-0.20)\end{array}$ & $9 \cdot 7$ \\
\hline
\end{tabular}


Table 4. Multiple, regression-derived coefficients $(\beta)$ and standard errors (SE) of specified predictors for the two principal components, PC1 and PC2* (From The EPIC-Elderly study)

\begin{tabular}{|c|c|c|c|c|c|c|}
\hline \multirow[b]{2}{*}{ Characteristics } & \multicolumn{3}{|c|}{ PC1: 'Vegetable-based' diet } & \multicolumn{3}{|c|}{ PC2: 'Sweet- and fat-dominated' diet } \\
\hline & $\beta$ & SE & Two-sided $P$ value & $\beta$ & SE & Two-sided $P$ value \\
\hline \multicolumn{7}{|l|}{ Gender } \\
\hline Males & Baseline & & & Baseline & & \\
\hline Females & 0.12 & 0.01 & $<10^{-3}$ & 0.35 & 0.01 & $<10^{-3}$ \\
\hline \multicolumn{7}{|l|}{ Age (years) } \\
\hline $60-64$ & Baseline & & & Baseline & & \\
\hline $65-69$ & -0.04 & 0.01 & $<10^{-3}$ & 0.04 & 0.01 & $<10^{-3}$ \\
\hline $70+$ & -0.09 & 0.01 & $<10^{-3}$ & $0 \cdot 10$ & 0.01 & $<10^{-3}$ \\
\hline \multicolumn{7}{|l|}{ Educational achievement } \\
\hline None/primary school completed & Baseline & & & Baseline & & \\
\hline Technical/vocational school completed & 0.13 & 0.01 & $<10^{-3}$ & 0.02 & 0.02 & 0.063 \\
\hline Secondary school completed & 0.20 & 0.01 & $<10^{-3}$ & 0.04 & 0.02 & 0.001 \\
\hline Higher degree & 0.26 & 0.01 & $<10^{-3}$ & -0.03 & 0.02 & 0.015 \\
\hline BMI (per $3 \mathrm{~kg} / \mathrm{m}^{2}$ increment) & 0.01 & 0.003 & $<10^{-3}$ & -0.04 & 0.003 & $<10^{-3}$ \\
\hline Waist:hip ratio† (per 0.5 units increment) & -0.10 & 0.03 & $<10^{-3}$ & -0.58 & 0.03 & $<10^{-3}$ \\
\hline Energy intake (per $1257 \mathrm{~kJ}$ increment) & 0.08 & 0.002 & $<10^{-3}$ & 0.10 & 0.002 & $<10^{-3}$ \\
\hline \multicolumn{7}{|l|}{ Physical activity at work } \\
\hline Unemployed & Baseline & & & Baseline & & \\
\hline Sedentary occupation & 0.14 & 0.01 & $<10^{-3}$ & -0.03 & 0.01 & 0.023 \\
\hline Standing occupation & 0.01 & 0.01 & 0.195 & 0.003 & 0.01 & 0.813 \\
\hline Manual work & $0 \cdot 10$ & 0.01 & $<10^{-3}$ & -0.08 & 0.02 & $<10^{-3}$ \\
\hline Heavy manual work & 0.04 & 0.03 & $0 \cdot 180$ & -0.22 & 0.03 & $<10^{-3}$ \\
\hline \multicolumn{7}{|l|}{ Physical activity at leisure time } \\
\hline 1st tertile & Baseline & & & Baseline & & \\
\hline 2nd tertile & 0.06 & 0.01 & $<10^{-3}$ & -0.01 & 0.01 & 0.525 \\
\hline 3rd tertile & 0.11 & 0.01 & $<10^{-3}$ & 0.02 & 0.01 & 0.043 \\
\hline \multicolumn{7}{|l|}{ Smoking status } \\
\hline Never smoked & Baseline & & & Baseline & & \\
\hline Past smoker & 0.08 & 0.01 & $<10^{-3}$ & -0.13 & 0.01 & $<10^{-3}$ \\
\hline Current smoker & -0.08 & 0.01 & $<10^{-3}$ & -0.32 & 0.01 & $<10^{-3}$ \\
\hline \multicolumn{7}{|l|}{ Participating centre } \\
\hline France (overall) & Baseline & & & Baseline & & \\
\hline Florence (Italy) & 1.70 & 0.02 & $<10^{-3}$ & 0.004 & 0.03 & 0.873 \\
\hline Varese (Italy) & 1.63 & 0.02 & $<10^{-3}$ & 0.28 & 0.03 & $<10^{-3}$ \\
\hline Ragusa (Italy) & $2 \cdot 28$ & 0.05 & $<10^{-3}$ & 0.18 & 0.05 & $<10^{-3}$ \\
\hline Turin (Italy) & 2.03 & 0.03 & $<10^{-3}$ & $0 \cdot 19$ & 0.03 & $<10^{-3}$ \\
\hline Naples (Italy) & 1.50 & 0.04 & $<10^{-3}$ & 0.37 & 0.04 & $<10^{-3}$ \\
\hline North Spain (Oviedo, Pamplona, San Sebastian) & 1.96 & 0.02 & $<10^{-3}$ & -0.26 & 0.02 & $<10^{-3}$ \\
\hline South Spain (Granada, Murcia) & 1.64 & 0.03 & $<10^{-3}$ & 0.25 & 0.03 & $<10^{-3}$ \\
\hline Cambridge (UK) & -1.41 & 0.02 & $<10^{-3}$ & 1.59 & 0.02 & $<10^{-3}$ \\
\hline Oxford (health-conscious; UK) & -0.62 & 0.02 & $<10^{-3}$ & 1.94 & 0.02 & $<10^{-3}$ \\
\hline Oxford (general population; UK) & -1.20 & 0.04 & $<10^{-3}$ & 1.40 & 0.04 & $<10^{-3}$ \\
\hline The Netherlands (overall) & -1.33 & 0.02 & $<10^{-3}$ & 0.32 & 0.02 & $<10^{-3}$ \\
\hline Greece (overall) & $2 \cdot 79$ & 0.02 & $<10^{-3}$ & 0.90 & 0.02 & $<10^{-3}$ \\
\hline Heidelberg (Germany) & $-1 \cdot 30$ & 0.02 & $<10^{-3}$ & -0.23 & 0.02 & $<10^{-3}$ \\
\hline Potsdam (Germany) & -1.65 & 0.02 & $<10^{-3}$ & -0.14 & 0.02 & $<10^{-3}$ \\
\hline Malmö (Sweden) & $-2 \cdot 19$ & 0.01 & $<10^{-3}$ & 1.21 & 0.02 & $<10^{-3}$ \\
\hline Umeå (Sweden) & -1.98 & 0.02 & $<10^{-3}$ & 1.64 & 0.02 & $<10^{-3}$ \\
\hline Denmark (overall) & -1.69 & 0.01 & $<10^{-3}$ & -1.25 & 0.02 & $<10^{-3}$ \\
\hline
\end{tabular}

*From the initial 99744, 10184 individuals were excluded owing to missing values for the variables of educational level, physical activity at work and at leisure, and smoking status.

†For some individuals, values for waist:hip ratio were imputed from a linear regression model with age, weight and height as independent variables and waist:hip ratio as the dependent variable.

(Heidelberg and Potsdam) and The Netherlands scored about the same as France in this component, and Denmark was characterised by the largest, in absolute value, negative scoring coefficient on PC2 (i.e. the elderly in Denmark consume high quantities of alcoholic beverages, meat, bread and eggs).

To examine further the adherence of the elders of each participating country to the dietary patterns implicit in PC1 and PC2, the graph of the respective mean scores (plotted one against the other) is shown in Fig. 1. Centre-specific mean scores are denoted by circles whose area is proportional to the size of the respective cohort. Centres in southern Europe are concentrated in the far right part of the graph, identified by high positive scores on $\mathrm{PC} 1$, and scores on $\mathrm{PC} 2$ that range from small positive (Greece) to around zero (Naples and Varese) and small negative (Southern Spain, Florence, Turin, Ragusa and Northern Spain). France is low but positive on PC1 and about zero on PC2.

The left-hand side of the graph depicts all northern European centres (apart from the Oxford health-conscious group). 


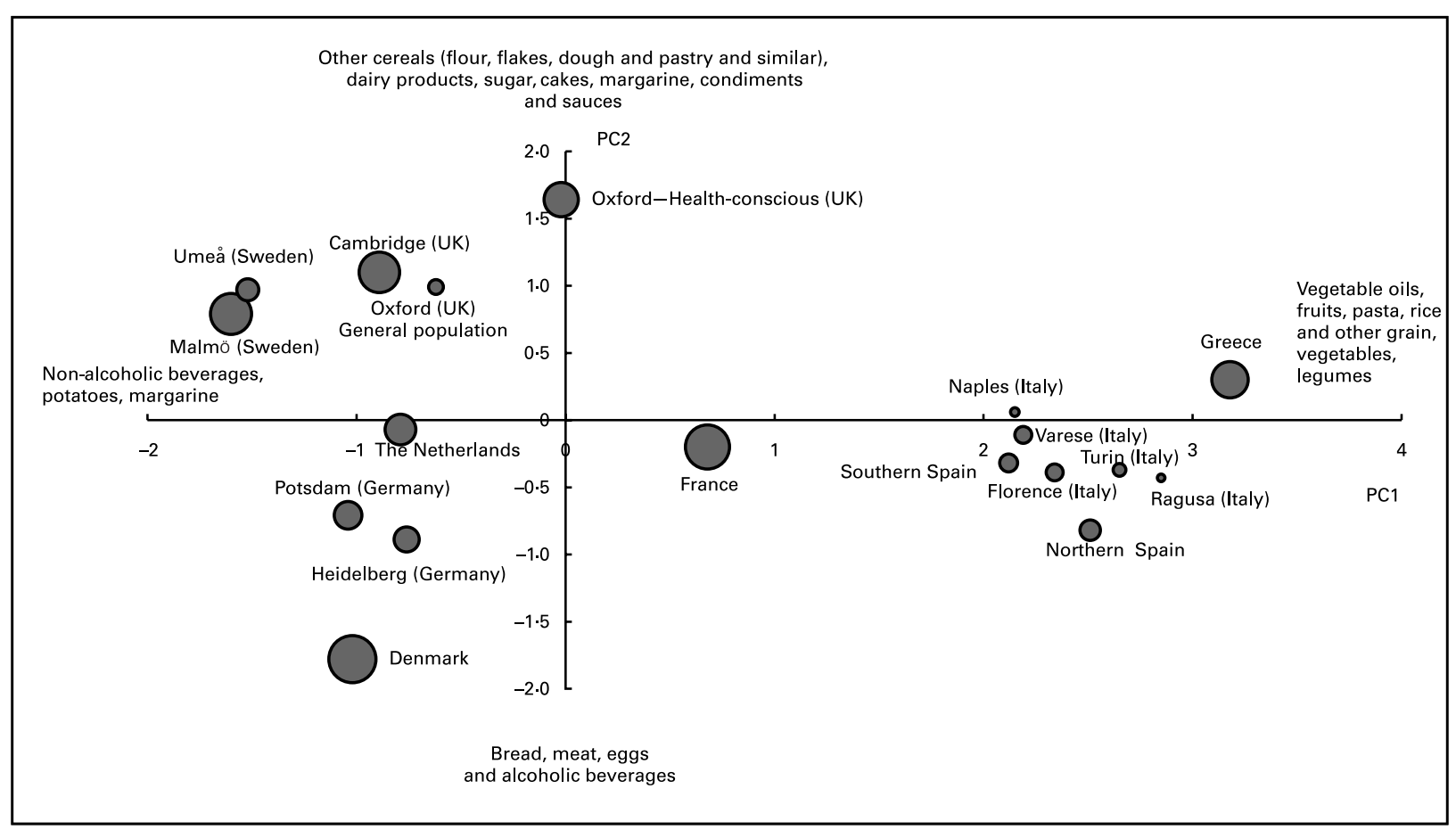

Fig. 1. Mean score of principal component 1 (PC1) and principal component 2 (PC2) by participating centre. (•) denote centre-specific mean scores, the size of the circles being proportional to the size of the respective cohort (From The EPIC-Elderly study).

The common element in this set of centres is that the respective populations of elders score negatively on PC1, i.e. they tend to consume margarine, potatoes and non-alcoholic beverages, and tend not to consume vegetable oils and foods of plant origin (apart from potatoes). The Oxford health-conscious cohort has a zero score on PC1, indicating a dietary pattern with no particular emphasis on any of the foods that define the positive or negative 'vegetable-based' scores. With respect to PC2, northern centres are spread across the PC2 axis, indicating that different northern countries 'belong' to different centiles of the distribution of this score. Thus, elders in Sweden and the UK prefer sweets, dairy products, condiments and margarine but not meat, bread, alcohol and eggs, whereas those in Denmark, and to a lesser degree Germany, follow the opposite pattern of consumption. Finally, The Netherlands is not characterised by any of the foods that are responsible for the extreme values (positive and negative) on PC2. Countries in southern Europe have in general small (mainly negative) or zero PC2 scores which vary, Northern Spain having the highest negative value in this component among the European southern countries.

Three major clusters emerged from cluster analyses using the criteria described in the Materials and Methods section, and are depicted in Fig. 2. Cluster A was characterised by a high consumption of vegetables, legumes, fruit, pasta, rice and other grain, vegetable oils and wine, and a low consumption of potatoes, butter, margarine, dairy products, meat, sugar, cakes, nonalcoholic beverages and alcoholic beverages except for wine. In contrast, cluster B was characterised by a high consumption of potatoes, other cereals (flour, pastry, breakfast cereals and similar), butter, margarine, sugar and cakes, and a low consumption of vegetables, legumes, pasta, rice and other grains, fruit, and vegetable oils. Cluster $\mathrm{C}$ was characterised by a fairly similar pattern of dietary intake to that of cluster B. What distinguished clusters $\mathrm{B}$ and $\mathrm{C}$ was the consumption of other cereals (flour, breakfast cereals, pastry and similar), butter, margarine, sugar and cakes, which was lower in cluster $\mathrm{C}$ than in cluster $\mathrm{B}$, and the consumption of eggs, non-alcoholic beverages and alcoholic beverages except for wine, which was higher in cluster $\mathrm{C}$ than in cluster B. The number of elders in clusters A, B and C was 18 562, 41912 and 39270, respectively.

Fig. 3 shows the mean scores of PC1 and PC2 for elders grouped into clusters $\mathrm{A}, \mathrm{B}$ and $\mathrm{C}$. There were remarkable differences with respect to the means of $\mathrm{PC} 1$ between clusters $\mathrm{A}$ and $\mathrm{B}$, and $\mathrm{A}$ and $\mathrm{C}$, whereas differences in mean PC2 between the three clusters were less striking. Thus, the odds of an individual belonging to the highest (compared with the lowest) quintile of PC1 were more than 100-fold if the individual was classified into cluster A compared with either cluster B or C, whereas the corresponding odds for PC2 were 1.8 and 4.2 times higher for elders allocated to cluster B than cluster A or C, respectively.

Expanding on the relations between PC and clusters, a much higher mean score for the first PC occurred in cluster A compared with the other two clusters. This, together with the practically zero mean score for PC2 estimated in this cluster, indicates that elders of cluster A tend overwhelmingly to follow the 'vegetable-based' diet. Regarding cluster B, the negative mean value for $\mathrm{PC} 1$ and the positive mean value for PC2 denote that the 'sweet- and fat-dominated' rather than the 'vegetable-based' is the diet of choice for elders belonging to this cluster. The negative value for PC1 in this cluster reflects the additional consumption of food groups such as potatoes, which characterise this cluster and have negative scoring coefficients in the definition of PC1. Finally, both PC1 and PC2 have negative mean values for cluster C. Thus, the diet of this cluster of elders is neither 


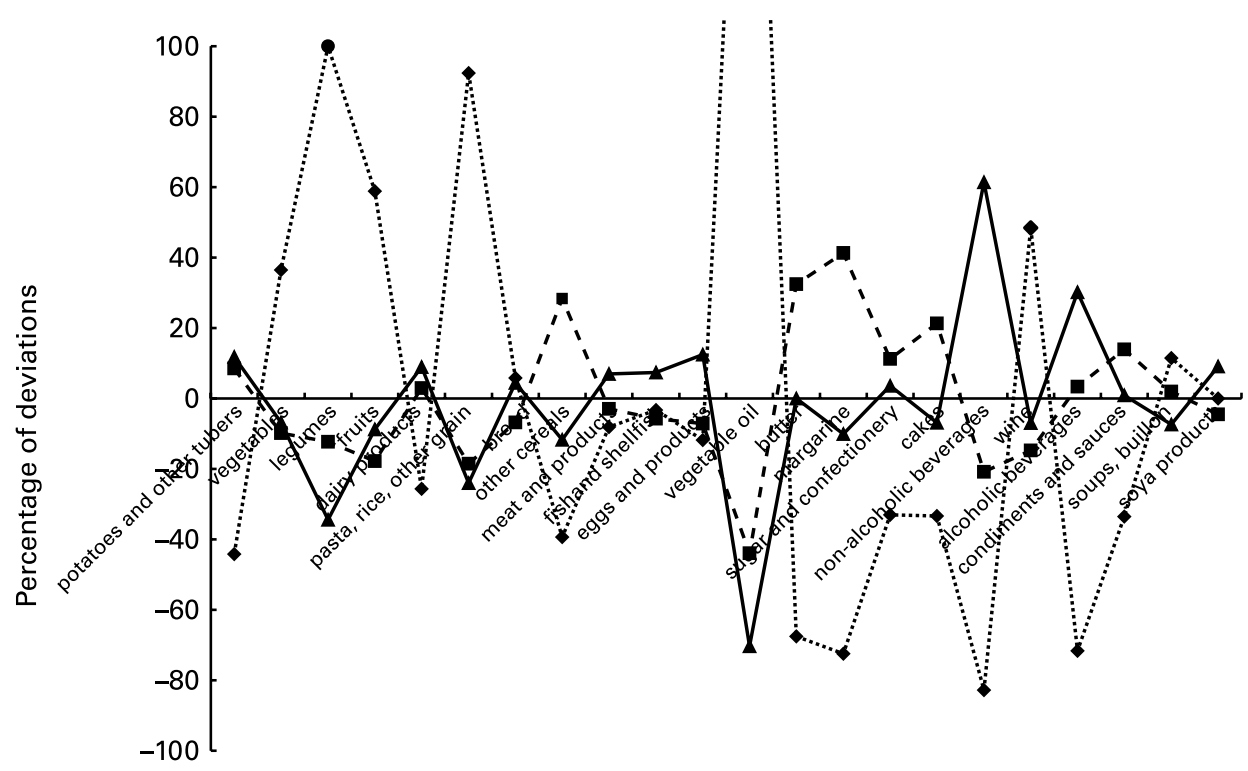

Food groups

Fig. 2. Three clusters of the study participants on the basis of their dietary intakes of twenty-two food groups. The vertical axis indicates percentage deviations of the within-cluster mean dietary intakes of each food group from the corresponding overall mean intakes (From The EPIC-Elderly study ... Cluster A (18562 subjects), --- Cluster B (41912 subjects), - Cluster C (39270 subjects)).

'vegetable-based' nor 'sweet- and fat-dominated' but emerges from food groups with negative scoring coefficients on both PC1 and PC2, i.e. potatoes, margarine, non-alcoholic beverages and alcoholic beverages (except for wine), meat and eggs.

Fig. 4 presents the distribution of elders of each participating centre to the three identified clusters. EPIC-Elderly participants of centres in Italy, Spain and Greece belonged almost entirely to cluster A, i.e. they appeared to have an overwhelming preference for the 'vegetable-based' diet. The rest of the EPIC-Elderly population was divided between clusters B and C (but not A). Elders who lived in France and in northern Europe were grouped into clusters B and C in fairly similar proportions, with the exception of Umeå (Sweden) and Denmark, whose elderly populations belonged almost entirely to clusters B and C, respectively. There were no major differences between centres within a country, except for Sweden.

\section{Discussion}

We have explored energy-adjusted dietary patterns in a large European population sample, aged 60 years or more at recruitment, and we have investigated their relation to socio-demographic and lifestyle characteristics. We have identified two major PC that express contrasts between certain food groups: a 'vegetable-based' dietary pattern with an emphasis on foods of plant origin rather than on margarine, potatoes and non-alcoholic beverages, and a 'sweetand fat-dominated' diet with a preference for sweets and dairy products but not meat, alcohol, bread and eggs. Thus, although two PC have been extracted from our data, the diets of elderly Europeans can be classified into more than two dietary patterns based on the combination of their scores for PC1 and PC2.

The 'vegetable-based' diet was preferred by younger, female, non-smoking subjects with a higher educational level, higher

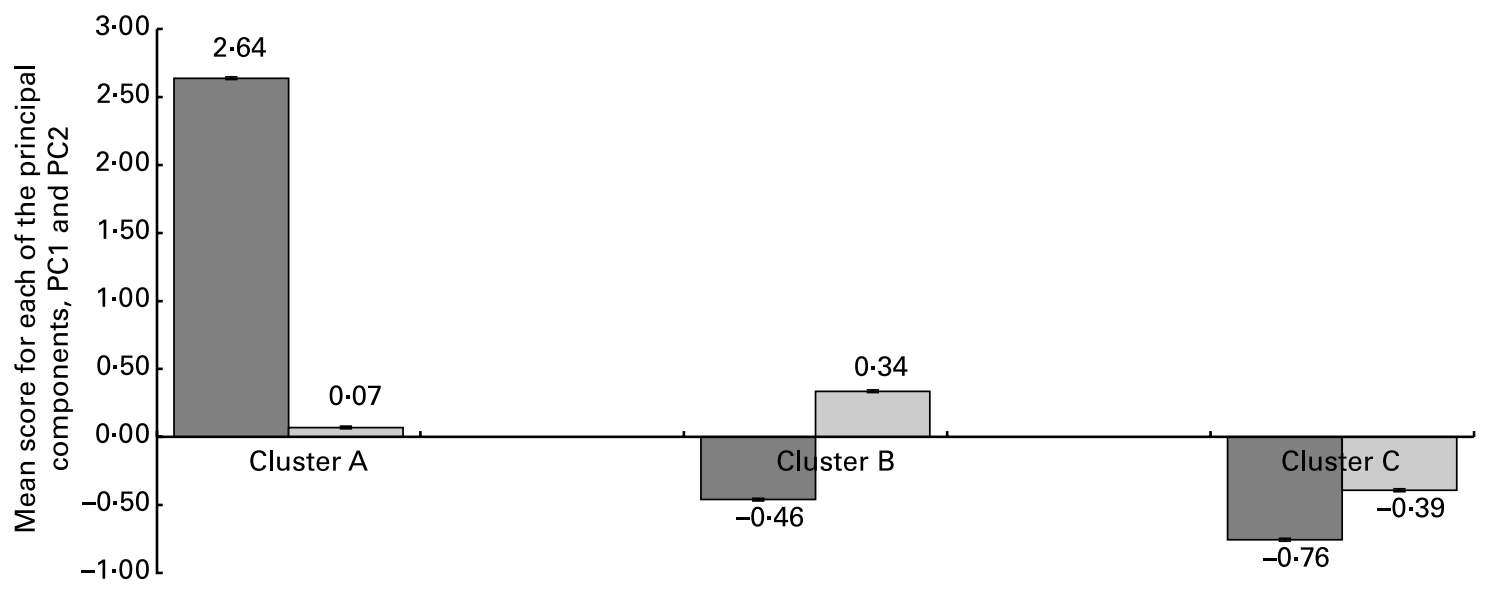

\section{Clusters}

Fig. 3. Mean scores of the two principal components PC1 $(\square)$ and PC2 $(\square)$ in clusters of individuals with similar dietary intakes in the EPIC-Elderly population (cluster A v. cluster B v. cluster C) (From The EPIC Elderly study). 


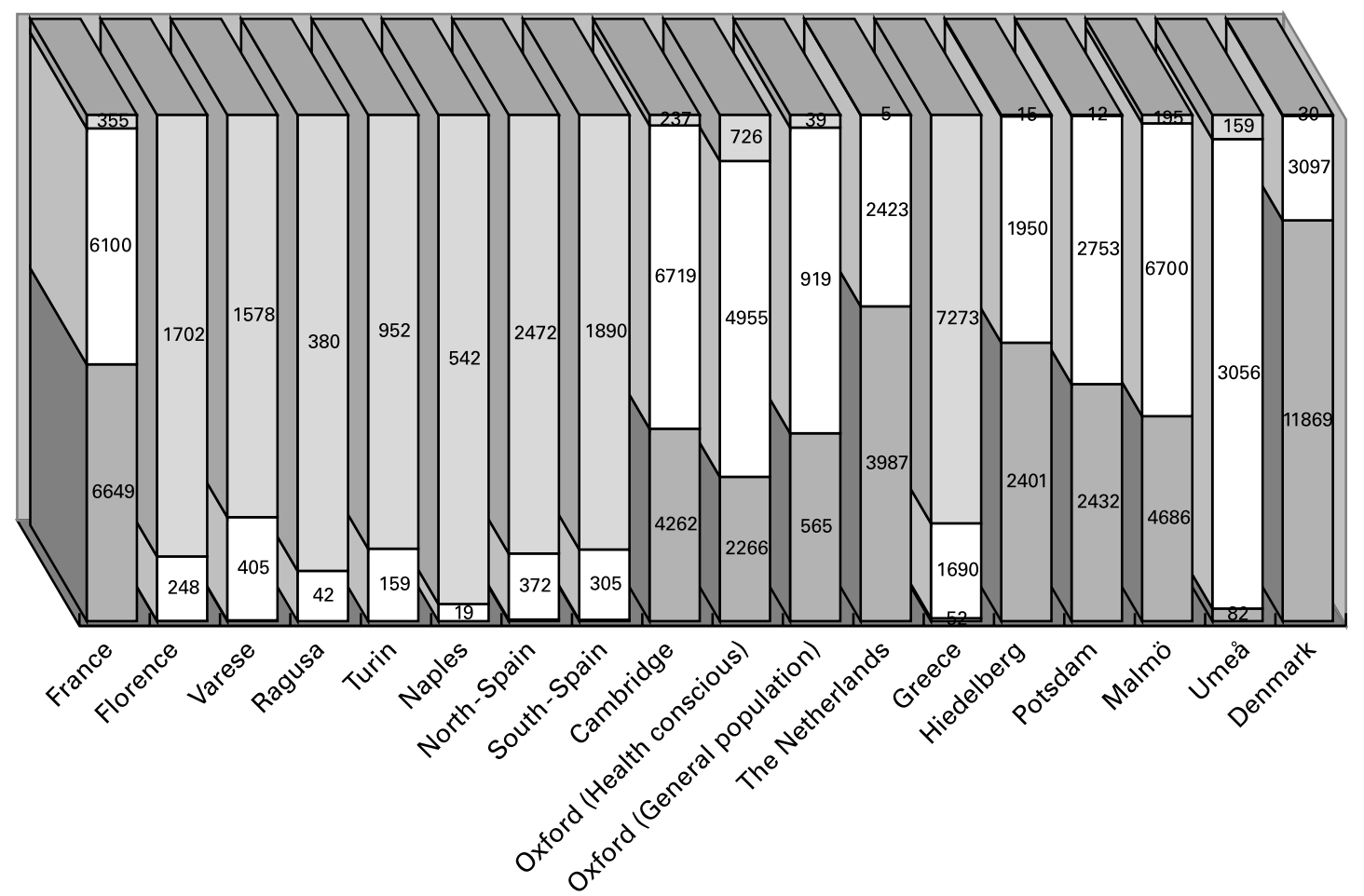

Participating centres

Fig. 4. Distribution of the EPIC-Elderly population by participating centre and identified cluster $\square$ Cluster A (18562 subjects), $\square$ Cluster B (41912 subjects), $\mathbb{Q}$ Cluster C (39270 subjects) (From The EPIC Elderly study).

BMI but lower waist:hip ratio and higher physical activity. It seems that this diet represents the choice of the educated and health-conscious elderly Europeans. A south-north gradient was also fully identifiable by PC1. High positive scores of this component denote a high consumption of food groups that are part of the traditional Mediterranean diet. Thus, countries of southern Europe, notably Spain, Italy and Greece, received the highest overall scores for this dietary pattern. France was less 'vegetable-based' than the rest of the Mediterranean counties. The dietary choices of the health-conscious elderly from Oxford were neutral with respect to this dietary pattern (score on PC1 about zero); in contrast, negative scores on PC1 were evident in the rest of the northern European centres, indicating that older individuals in these countries consume potatoes, non-alcoholic beverages and margarine, and fewer vegetable oils or foods of plant origin. Thus, the 'vegetable-based' diet varies with geography, as well as with education and socio-cultural factors (de Groot et al. 1996).

The 'sweet- and fat-dominated' diet reflected the dietary choice of older female elders with a low educational achievement, who had never been smokers and who had a low BMI but also a low level of physical activity. Scores on PC2 discriminate between participants from northern and from southern Europe. Thus, elderly from the UK and Sweden receive high PC2 scores because they follow diets rich in dairy products, sweets, savoury snacks and margarine, whereas they refrain from consuming bread, meat, eggs and alcohol. The opposite pattern of consumption, which closely resembles what has been labelled as the 'Western diet' in previous studies (Slattery et al.1998; Hu et al. 1999; Fung et al. 2001a,b; Osler et al. 2001; Terry et al. 2001; Costacou et al. 2003), is evident in Germany and Denmark. Elderly individuals from The Netherlands score zero on PC2, indicating that they do not have any particular preference for foods deemed important for this component. In southern Europe, PC2 scores are small in absolute value, are mostly negative and vary between centres. Thus, the consumption of meat, bread, alcohol and eggs is low among the Mediterranean elderly but varies, with Northern Spain having a relatively high consumption of some of these foods, particularly eggs, meat and meat products. The distribution of PC2 scores among the Mediterranean countries can thus be seen as an indicator of the degree of evolution in the traditional diets of these countries towards a more Western-type diet.

We have also identified clusters of elderly who share similar dietary behaviour and who are identifiable by the mean scores of the extracted PC. Elders in cluster A are distinct from individuals outside this cluster in terms of their preference for the "vegetable-based' pattern and their relative antipathy towards foods that characterise PC2. In contrast, elders in clusters B and C share some dietary choices, as indicated by the negative mean value of PC1 in both clusters, and they differ only with respect to those food components which are responsible for the extreme scores on the 'sweet- and fat-dominated' diet: individuals in cluster B consume high quantities of other cereals (flour, breakfast cereals, pastry and similar), margarine, sugar, cakes and condiments and sauces (positive scores on PC2), whereas elderly in cluster $\mathrm{C}$ consume meat and products, eggs and alcoholic beverages (negative scores on PC2). Regarding the distribution of 
centres into the three clusters, Mediterranean countries were segregated into cluster A. Northern Europeans belong exclusively to clusters B and C, but both clusters are represented in almost all northern centres.

Several attempts have been made to classify dietary choices and consumptions into dietary patterns with a posteriori approaches. PC analysis and the closely related factor analysis have previously been used in nutritional research carried out in Europe (Prevost et al. 1997; Schulze et al. 2001; Balder et al. 2003; Costacou et al. 2003) and in the USA (Hu et al. 1999; McCann et al. 2001). In contrast, previous studies that focused on the diet of the elderly have used almost exclusively cluster analysis (Tucker et al. 1992; Huijbregts et al. 1995; Schroll et al. 1996; Havemann-Nies et al. 1998, 2001; Lin et al. 2003). Since no optimal method exists to classify dietary patterns, we have used both analytical approaches. Our results from PC and cluster analyses converge on the same conclusions; however, the classification of countries into different patterns was clearer using PC analysis. Nevertheless, cluster analysis in combination with PC analysis allowed us to evaluate how consistent a particular type of diet was within geographical regions. The resulting dietary choices of elderly Europeans, as defined by PC analysis, are compatible with those reported for a random sample of participants aged 34-75 years from the total EPIC cohort, whose dietary intakes were assessed by $24 \mathrm{~h}$ dietary recall interviews (Slimani et al. 2002b).

Whereas an a posteriori approach may seem an objective way to investigate dietary patterns, its use in nutritional epidemiology has raised certain concerns (Martinez et al. 1998). In PC analyses, essential decisions include the initial selection of dietary variables, the decision to standardise the dietary variables and the number of components to be retained. Moreover, the amount of total variance that is usually explained by the extracted PC or factors is very small (up to $30 \%$ ). Cluster analysis, in addition, is strongly dependent on the clustering method. Nevertheless, the north-south gradient that we observed in our data, as well as the identified clusters, were comparable to the results previously reported for the elderly. Cluster A was similar to the 'healthy diet' cluster identified by Huijbregts et al. (1995), whereas a 'sugar- and fat-dominated' cluster approximating our cluster B was evident in studies by Schroll et al. (1996), Haveman-Nies et al. (2001) and Huijbregts et al. (1995). Tucker et al. (1992) and Lin et al. (2003) did not identify clusters similar to ours in analyses of a US population of elderly, possibly owing to different diets in Europe and the USA.

Regarding the extracted PC, our findings are compatible with results from PC analyses of centre-specific EPIC cohorts: Costacou et al. (2003) also identified a 'Mediterranean' and a very similar 'vegetarian' diet, as well as a 'sweet-based' dietary pattern in the Greek population of EPIC participants. The PC identified by Schulze et al. (2001) for the EPIC-Potsdam study were not identical to ours, but they were based on forty-nine original food items selected on the basis of culinary usage. The same holds for Balder et al. (2003), who analysed four European cohorts and used food items very different from ours. Dietary components named 'prudent' or 'healthy', which are similar to our 'vegetable-based' diet, have been identified by many studies in Europe (Osler et al. 2001 in Denmark, Sieri et al. 2004 in Italy, Terry et al. 2001 in Sweden) and the USA (Slattery et al. 1998; Hu et al. 1999; Fung et al. 2001a,b). A 'sweet-' and a 'fat-' dominated diet were also evident in the study by Slattery et al. (1998), whereas the 'Western' diet that was discernible in our study (Fig. 1) was also evident in most of the above studies.

Along the same lines, the positive associations between the 'vegetable-based' diet and educational achievement and physical activity, and the inverse association of this diet with current smoking, have also been reported from studies that have focused on 'healthy' or 'prudent' dietary patterns. The inverse associations of the 'sweet- and fat-dominated' diet with physical activity, smoking and BMI have all been reported by Costacou et al. (2003), whereas Slattery et al. (1998) also found an inverse association between their 'high-fat/sugar dairy' pattern and BMI. As indicated, it is not easy to compare dietary patterns resulting from a posteriori analytical approaches across studies because of the different food groups that were originally selected, the different assessment and analytical tools used in the respective countries and different decision criteria for the extracted clusters, or components.

Our study has described the dietary patterns of Europeans of 60 years of age or older who live in nine different European countries. These patterns can be used as covariates when examining a specific nutrient in order to explore whether the nutrientrelated effect is independent of the overall dietary patterns $(\mathrm{Hu}$ et al. 1999). Whether a posteriori patterns can be used as a standard approach in order to describe disease associations is, however, questionable (McCann et al. 2001; Martinez et al. 1998).

Among the advantages of the present study are its large size, its reliance on a sample from European populations of nine countries with considerable variability on several characteristics, the use of within-country validated food-frequency questionnaires, and the standardised measurement of all examined variables across participating centres. Disadvantages of the study are the inherent problems in dietary assessment, the lack of representativeness of some cohorts, the questionable robustness of cluster analysis, and the generic problems underlying the $a$ posteriori approach.

In conclusion, we have identified in a large sample of elderly Europeans 'vegetable-based' and 'sweet- and fat-dominated' PC. We have classified the dietary habits of European elders based on combinations of scores of these components, and we have determined their lifestyle and socio-demographic predictors. We have also identified three clusters of individuals whose dietary behaviour is fairly similar within clusters and fairly different between clusters, and we have found that the three clusters are identifiable by the respective PC. Our study thus highlights the dietary patterns prevailing among the elderly across Europe and contributes to the identification of groups that are likely to have different prospects for long-term disease occurrence and survival.

\section{Acknowledgements}

This study was supported by the Quality of Life and Management of Living Resources Programme of the European Commission (DG Research, contract No QLK6-CT-2001-00 241) for the project EPIC-Elderly, coordinated by the Department of Hygiene and Epidemiology, University of Athens Medical School; the Europe against Cancer Programme of the European Commission, (DG SANCO) for the project EPIC coordinated by the International Agency for Research on Cancer (WHO); the Greek Ministry of Health and the Greek Ministry of Edu- 
cation (Greece); a fellowship honouring Vasilios and Nafsika Tricha (Greece); The Danish Cancer Society (Denmark); Ligue contre le Cancer (France); Société 3M (France); Mutuelle Générale de 1'Education Nationale (France); Institut National de la Santé et de la Recherche Médicale (INSERM) (France); Gustave Roussy Institute and several General Councils in France (France); German Cancer Aid (Germany); German Cancer Research Center (Germany); German Federal Ministry of Education and Research (Germany); Associazione Italiana per la Ricerca contro il Cancro (AIRC) Milan (Italy); Compagnia di San Paolo (Italy); Regione Sicilia and Avis-Ragusa (Italy); the Dutch Ministry of Public Health, Welfare and Sports (the Netherlands); the Health Research Fund (FIS) of the Spanish Ministry of Health (Spain); the Spanish Regional Governments of Andalucia, Asturias, Basque Country, Murcia and Navarra (Spain); the ISCIII Network Red de Centros RCESP (C03/09; Spain); the Swedish Cancer Society (Sweden); the Swedish Scientific Council, City of Malmö, (Sweden); the Regional Government of Skåne, (Sweden); Cancer Research, UK (UK); and the Medical Research Council (UK). The author(s) is (are) solely responsible for the publication, and the publication does not represent the opinion of the community. The community is not responsible for any use that might be made of data appearing in this work.

\section{References}

Balder HF, Virtanen M, Brants HA, et al. (2003) Common and countryspecific dietary patterns in four European cohort studies. J Nutr 133, $4246-4251$.

Chatfield C \& Collins AJ (1995) Introduction to Multivariate Analysis [C Chatfield and JV Zidek, editors]. London: Chapman \& Hall.

Costacou T, Bamia C, Ferrari P, Riboli E, Trichopoulos D \& Trichopoulou A (2003) Tracing the Mediterranean diet through principal components and cluster analyses in the Greek population. Eur J Clin Nutr 57, 1378-1385.

de Groot LC, van Staveren WA \& Burema J (1996) Survival beyond age 70 in relation to diet. Nutr Rev 54, 211-212.

Euronut-SENECA (1991) Nutrition and the elderly in Europe. 1st European Congress on Nutrition and Health in the Elderly. The Netherlands, December 1991. Eur J Clin Nutr 45, Suppl. 3, 1-196.

Fung TT, Rimm EB, Spiegelman D, Rifai N, Tofler GH, Willett WC \& Hu FB (2001a) Association between dietary patterns and plasma biomarkers of obesity and cardiovascular disease risk. Am J Clin Nut 73, 61-67.

Fung TT, Willett WC, Stampfer MJ, Manson JA \& Hu FB (2001b) Dietary patterns and the risk of coronary heart disease in women. Arch Intern Med 161, 1857-1862.

Haines PS, Siega-Riz AM \& Popkin BM (1999) The Diet Quality Index revised: a measurement instrument for populations. J Am Diet Assoc 99, 697-704.

Haveman-Nies A, de Groot LP \& van Staveren WA (1998) Snack patterns of older Europeans. J Am Diet Assoc 98, 1297-1302.

Haveman-Nies A, Tucker KL, de Groot LC, Wilson PW \& van Staveren WA (2001) Evaluation of dietary quality in relationship to nutritional and lifestyle factors in elderly people of the US Framingham Heart Study and the European SENECA study. Eur J Clin Nut 55, $870-880$.

Hu FB, Rimm E \& Smith-Warner SA (1999) Reproducibility and validity of dietary patterns assessed with a food-frequency questionnaire. Am J Clin Nutr 69, 243-249.

Hu FB, Rimm EB, Stampfer MJ, Ascherio A, Spiegelman D \& Willett WC (2000) Prospective study of major dietary patterns and risk of coronary heart disease in men. Am J Clin Nutr 72, 912-921.
Hu FB \& Willett WC (2002) Optimal diets for prevention of coronary heart disease. JAMA 288, 2569-2578.

Huijbregts PP, Feskens EJ \& Kromhout D (1995) Dietary patterns and cardiovascular risk factors in elderly men: the Zutphen Elderly Study. Int $J$ Epidemiol 24, 313-320.

Huijbregts P, Feskens E, Rasanen L, Fidanza F, Nissinen A, Menotti A \& Kromhout D (1997) Dietary pattern and 20 year mortality in elderly men in Finland, Italy, and the Netherlands: longitudinal cohort study. BMJ 315, 13-17.

Kant AK, Schatzkin A, Graubard BI \& Schairer C (2000) A prospective study of diet quality and mortality in women. JAMA 283, 2109-2115.

Kennedy ET, Ohls J, Carlson S \& Fleming K (1995) The Healthy Eating Index: design and applications. J Am Diet Assoc 95, 1103-1108.

Key TJ, Schatzkin A, Willett WC, Allen NE, Spencer EA \& Travis RC (2004) Diet nutrition and the prevention of cancer. Publ Health Nutr 7, 187-200.

Kumagai S, Shibata H, Watanabe S, Suzuki T \& Haga H (1999) Effect of food intake pattern on all-cause mortality in the community elderly: a 7-year longitudinal study. J Nutr Health Aging 3, 29-33.

Lin H, Bermudez OI \& Tucker KL (2003) Dietary patterns of Hispanic elders are associated with acculturation and obesity. Nutrition 133, 3651-3657.

McCann SE, Weiner J, Graham S \& Freudenheim JL (2001) Is principal components analysis necessary to characterise dietary behaviour in studies of diet and disease? Publ Health Nutr 4, 903-908.

McCullough ML, Feskanich D, Stampfer MJ, Giovannucci EL, Rimm EB, Hu FB, Spiegelman D, Hunter DJ, Colditz GA \& Willett WC (2002) Diet quality and major chronic disease risk in men and women: moving toward improved dietary guidance. Am J Clin Nutr 76, 1261-1271.

Mann JI (2002) Diet and risk of coronary heart disease and type 2 diabetes. Lancet 360, 783-789.

Martinez ME, Marshall JR \& Sechrest L (1998) Invited commentary: factor analysis and the search for objectivity. Am J Epidemiol 148, $17-19$.

Martinez-Gonzalez MA, Fernandez-Jarne E, Serrano-Martinez M, Marti A, Martinez JA \& Martin-Moreno JM (2002) Mediterranean diet and reduction in the risk of a first acute myocardial infarction: an operational healthy dietary score. Eur J Nutr 41, 153-160.

Osler M, Heitmann BL, Gerdes LU, Jørgensen LM \& Schroll M (2001) Dietary patterns and mortality in Danish men and women: a prospective observational study. Br J Nutr 85, 219-225.

Patterson RE, Haines PS \& Popkin BM (1994) Diet quality index: capturing a multidimensional behavior. J Am Diet Assoc 94, 57-64.

Prevost AT, Whichelow MJ \& Cox BD (1997) Longitudinal dietary changes between 1984-5 and 1991-2 in British adults: association with socio-demographic, lifestyle and health factors. Br J Nutr 78, $873-888$.

Riboli E, Hunt KJ, Slimani N, et al. (2002) European Prospective Investigation into Cancer and Nutrition (EPIC): study populations and data collection. Pubc Health Nutr 5, 1113-1124.

SAS Institute Inc. (1999) SAS/STAT User's Guide, Version 8. Cary, NC: SAS Institute, Inc.

Schroll K, Carbajal A, Decarli B, Martins I, Grunenberger F, Blauw YH \& de Groot CP (1996) Food patterns of elderly Europeans. SENECA Investigators. Eur J Clin Nutr 50, Suppl. 2, S86-S100.

Schulze MB, Hoffmann K, Kroke A \& Boeing H (2001) Dietary patterns and their association with food and nutrient intake in the Prospective Investigation into Cancer and Nutrition (EPIC)-Postdam Study. $\mathrm{Br} \mathrm{J}$ Nutr 85, 363-373.

Sieri S, Krogh V, Pala V, Muti P, Micheli A, Evangelista A, Tagliabue G \& Berrino F (2004) Dietary patterns and risk of breast cancer in the ORDET cohort. Cancer Epidemiol Biomarkers Prev 13, 567-572.

Slattery ML, Boucher KM, Caan BJ, Potter JD \& Ma KN (1998) Eating patterns and risk of colon cancer. Am J Epidemiol 148, 4-16.

Slimani N, Fahey M, Welch AA, et al. (2002b) Diversity of dietary patterns observed in the European Prospective Investigation into Cancer and Nutrition (EPIC) project. Publ Health Nutr 5, 1311-1328. 
Slimani N, Kaaks R, Ferrari P, et al. (2002a) European Prospective Investigation into Cancer and Nutrition (EPIC) calibration study: rationale, design and population characteristics. Publ Health Nutr 5, 1125-1145.

Srinath Reddy K \& Katan MB (2004) Diet, nutrition and the prevention of hypertension and cardiovascular diseases. Pubc Health Nutr 7, 167-186.

Stata Corporation (1999) Intercooled Stata 6.0 for Windows 98/95/NT. Texas: Stata Corporation.

Terry P, Hu FB, Hansen H \& Wolk A (2001) Prospective study of major dietary patterns and colorectal cancer risk in women. Am J Epidemiol 154, 1143-1149.

Trichopoulos D \& Lagiou P (2001) Dietary patterns and mortality. Br J Nutr 85, 133-134.
Trichopoulou A, Costacou T, Bamia C \& Trichopoulos D (2003) Adherence to Mediterranean diet and survival in a Greek population. $N$ Engl J Med 348, 2599-2608.

Trichopoulou A, Kouris-Blazos A, Wahlqvist ML, Gnardellis C, Lagiou P, Polychronopoulos E, Vassilakou T, Lipworth L \& Trichopoulas D (1995) Diet and overall survival in elderly people. BMJ 311, $1457-1460$

Tucker KL, Dallal GE \& Rush D (1992) Dietary patterns of elderly Boston-area residents defined by cluster analysis. J Am Diet Assoc 92, 1487-1491.

Willett WC (1998) Diet and coronary heart disease. In Nutritional Epidemiology, 2nd ed., pp. 414-466 [WC Willett, editor]. New York: Oxford University Press. 